\title{
THE ASSOCIATION BETWEEN ANXIETY, PHYSICAL EXERCISE, DIETARY PATTERN, AND PHYSICAL FITNESS AMONG MALE ADOLESCENTS: A PATH ANALYSIS STUDY
}

\author{
Hayu Andita Satriani'), Dono Indarto²), Yulia Lanti Retno Dewi3) \\ ${ }^{1)}$ Masters Program in Public Health, Universitas Sebelas Maret \\ 2)Department of Physiology, Faculty of Medicine, Universitas Sebelas Maret \\ 3)Department of Nutrition, Faculty of Medicine, Universitas Sebelas Maret
}

\begin{abstract}
Background: Obesity in adolescence is crucial as it represents an important stage in human life. The International Obesity Task Force report showed that a total of 155 million children and adolescents are overweight and around 30-45 million are classified as obese. Dietary habits are greatly associated with lifestyle. This study aimed to examine the association between anxiety, physical exercise, dietary pattern, and physical fitness among male adolescents.

Subjects and Method: This was a cross-sectional study conducted in three senior high schools, Gondokusuman, Yogyakarta. A sample of 225 male students aged $15-18$ years was selected by fixed exposure sampling. The dependent variable was physical fitness. The independent variables were body mass index (BMI), anxiety, physical exercise, and dietary pattern. Data on sleep quality were measured by Pittsburgh Sleep Quality Index (PSQI) questionnaire. Anxiety was measured by Hamilton Anxiety Rating Scale. Dietary pattern were measured by Frequency Food Questionnaire (FFQ). Physical fitness measured by Cooper run test 12 minutes. The data were analyzed by path analysis run on Stata 13 .

Results: Physical fitness was directly increased by good dietary pattern $(b=2.09 ; 95 \%$ $\mathrm{CI}=0.51$ to $3.68 ; \mathrm{p}=0.009)$ but decreased by $\mathrm{BMI}(\mathrm{b}=-3.53 ; 95 \% \mathrm{CI}=-4.49$ to -2.58 ; $\mathrm{p}<0.001)$. Physical fitness was indirectly affected by physical activity, quality of sleep, and anxiety.

Conclusion: Physical fitness is directly increased by good dietary pattern but decreased by BMI. Physical fitness is indirectly affected by physical activity, quality of sleep, and anxiety among adolescents.
\end{abstract}

Keywords: physical fitness, physical exercise, anxiety, dietary pattern, male adolescents

\section{Correspondence:}

Hayu Andita Satriani. Masters Program in Public Health, Universitas Sebelas Maret. Jl. Ir. Sutami 36 A, Surakarta, Central Java 57126. Email: hayuandita@gmail.com 